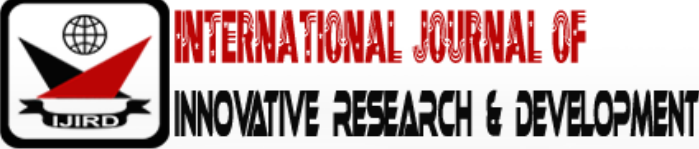

ISSN 2278 - 0211 (Online)

\section{Students’ Awareness of Social Networks Profile Usage in Screening and Selecting Job Applicants}

\author{
\begin{tabular}{c} 
Evans O. N. D. Ocansey, \\
Lecturer, School of Business, Valley View University, Ghana \\
Ama F. Karikari \\
Senior Lecturer, School of Business, Valley View University, Ghana \\
Abdulai Issaka, \\
Lecturer, School of Business, Valley View University, Ghana \\
\hline
\end{tabular}
}

\begin{abstract}
:
This study investigated the use of social network profile as a credible source of information for screening and selecting job applicants and the influence of students' social network behavior on their approval of employers'choice of recruitment. Final year students of all modes were sampled,and copies of thequestionnairewere administered. Data were analyzed with frequency distribution table, Pearson correlation, and regression model. It was foundthat students' awareness of the use of social network profile information of job applicants by employers, influences students' social network behavior but at aninsignificant level. Also, students' social network behavior insignificantly influences their approval of employers using job applicants' social network profile in screening and selection. Further, High GPA and female students exhibited good social networkbehavior. Based on the findings of the study, it is recommended that students should be mindful of their behavior on social networks since bad behavior can deny them their job.
\end{abstract}

Keywords: Social network, social network behavior, screening and selection, job application

\section{Introduction}

The revolution of technology including social networking websites (example Facebook, LinkedIn, YouTube, WhatsApp) has changed the means of communication, relationship development and organizational behavior (Derks \& Bakker, 2013; Kaplan \& Haenlein, 2010). This revolution has changed the functions of human resource management such as recruitment, screening, selection and even training and development (McFarland \& Plohart, 2015). Also, thesocial networkshave presented new opportunities for the accessibility of job applicants' profile information. That is, social networks have reduced the barriers to job applicants' information.

The human resources of institutions are the most important resources of every institution. They manage and control all other resources of an institution. However, creating a great and right pool of employees for an institution is one of the greatest challenges of human resource management (Ullah, 2010). Screening and selection play a major role in getting the right employees from the pool of employees for institutions. Moreover, screening and selecting the right employees from the generated pool of recruitment can enhance the effective and efficient performance of institutions. That is, generating a better pool of recruits can lead to better employees screened and selected, and better employees screened and selected can lead to higher performance. In other words, hiring the right employees for the right positions can enhance higher productivity, increase employee retention, reduce turnover costs, etc. That is, the success and failure of institutions depend greatly on their workforce. In other words, employees great lyinfluence institutional performance.

It is not easy to predict the future performance of potential employees, but their background history can help know how they are likely to behave and perform on the job. Screening and selecting to get the right workforce can help reduce fraud risk, prevent frauds and hiring incompetent employees, and hiring the right employees for the right job. Hiring the right person for the right job is very crucial to the success of every organization.

The emergence of social network websites and search engines has greatly impacted the decision on the staffing and selection of job applicants (Nye, Do, Drasgow \& Fine, 2008; Viswesvaran, 2003). Hence screening and selection of potential employees are greatly influenced by the use of social network websites and search engines. The growth of mobile devices such as smartphones, tablets, computers, and other portable media devices which encouraged the sharing of photos, music and videos ignited massive interest in the activities on social network websites. 
There are about 2.5 billion users of social network websites, and greater percent are the youth. The fastest users of social network websites include pre-teens, teens, and university students; largely and currently, the most common usages of the internet are social network participation (Laudon \& Traver, 2014). Though these users log on to social network websites to interact socially to create intimacy and build their identity among their peers online, they end up sharing a great deal of personal information. Also, some search engines require users to sign up before they access and download some information. Signing up for these search engines also collect personal information of users.

The use of social network websites and search engines by employers to uncover the personal information of job applicants for employment is on the increase. Employers believed that this technique of screening and selection could provide additional information that the traditional techniques cannot provide. Nonetheless, there are issues with the legality, the appropriateness, standardization, reliability, and validity of this practice (Davison, Maraist, Hamilton \& Bing, 2011).Research into online social networking and weblog usage revealed that there is a relationship between online users' profile information and their personality. It was also revealed that there is a relationship between language usage and personality of online usersas well as wall posts and their personality (Golbeck, Robles \& Turner, 2011; Sumner, Byers \& Shearing, 2011).

Screening and selection of employees are one of the most important issues to human resource practitioners (HRP) and academic researchers in the world.

Social network websites and search engines have become a great source of information for employers when screening and selecting job applicants. Personal information about potential employees at social network websites such as Facebook, LinkedIn, Twitter among others are used by employers to screen and select employees (Kluemper \& Rosen, 2009).The explosion of the use of social network website has greatly influenced the employee screening and selection of these website users due to a considerable number of personal information that can be accessed and assessed by many people. Though many (HRP) and researchers are highly interested in anointer view with employees to get the kind of employees they want, many are now focusing on screening their social network profiles before interviewing them. A survey conducted by Microsoft Corporation in the United States of America revealed that about eighty percent of recruiting professionals and agencies screen and evaluate job applicants based on their behavior, what they post and what others share with them on social network websites and search engines (CROSS TAB, January 2010)

Moreover, search engines such as Google, Yahoo,MSN and others also collect personal information. Employers engage in profile screening to increase the general quality of the pool of recruits. HRPs are critically examining the social network profiles of applicants and search engines before hiring and can accurately distinguish between high and low performers (Kluemper \& Rosen, 2009). However, many potential employees, especially university students who are using social network websites and search engines provide much personal information on these websites without considering the implications of the information provided. These students go to these websites to enjoy the social communities, search for information, and for reasons other than employment but the information provided on these platforms are sometimes accessed by different people for different purposes including screening and selection by employers. The use of social network profile information of job applicants in the screening and selection for employment raises questions on the accuracy of the information, invasion of privacy, variability and equality of applicants' information, identifiable theoretical construct and absent of data to support screening and selection (Broughton, Foley, Lendermaier \& Cox, 2013; Brown \& Vaughn, 2011)

Though there are some researches on social networks and pre-employment screening, most of the studies were done outside Ghana. Further, Ghana is one of the countries which are growing fast in the use of social networks and search engines. Majority of the users of the social network are university students (Sponcil\&Gitimu, 2013).There is as carcity of empirical researches onthe awareness of university students regarding the use of social network profile by employers in the screening and selection of job applicants. Also, there is a gap on the effect of students' awareness of the use of social network profile by employers in the screening and selection of job applicant son their behavior on social network websites. This research, therefore, seeks to fill these research gaps through the answering of the following questions:

- What is the students' awareness level of employers using the social network websites profiles of applicants before hiring job applicants.

- To what extent will students' awareness of social network profile evaluation in screening and selection of job applicants by employers influence their social network behavior

- What is the influence of students' social network behavior on students' approval of the use of social network profiles in the screening and selection of job applicants by employers

-

1.1. Research Hypotheses

- $\mathrm{H}_{0}$ 1:Students' awareness of social network profile evaluation of job applicants in screening and selection by employers has no significant influence on students' social network behavior

- $\mathrm{H}_{0}$ 2:Students' social network behavior has no significant influence on students' approval of employers use of social network profile evaluation in screening and selection of job applicants

The rest of the paper covers a review of related literature and studies relevant to this studies, methodology, and presentation of data and discussion. 


\section{Review of Literature}

A survey of 21 emerging and developing economies showed a median usage of $45 \%$ internet in 2013 and increased to 54\% in 2015 (Pew Research Center, 2016). The same report indicated that access to the internet is about $75 \%$ across 40 countries surveyed in 2015 with majority accessing the internet several times a day and $76 \%$ use social network websites such as Facebook and Twitter. Further, "younger, more-educated and higher-income people" (Pew Research Center, 2016) have greater access to the internet in various countries in the world.

The daily and weekly internet usage in Ghana as at 2015 was at 54\% (several times a day) and 30\% (at least once a week) and smartphones ownership have increased from 14\% in 2014 to 21\% in 2015 (Pew Research Center, 2016).The same report revealed that $77 \%$ of adults in Ghana were using social network websites in the year 2015.Social network as one of the components of social mediais described as an Internet-based application which allows the creation and exchange of generated content (Peters, Chen, Kaplan, Ognibeni \& Pauwels, 2013; Kaplan \& Haenlein, 2010)

\subsection{Social Network Websites Usage by Employers to Screen and Select Job Applicants}

Many recruiting professionals are using job applicants' reputation information online to assess a potential employee's lifestyle that might be questionable to the core values of the employer (Belluck, June 22, 2006). Moreover, a survey of employers indicated that, $78 \%$ of recruiting professionals use search engines, $63 \%$ of recruiters searched social network websites, $59 \%$ of the recruiters examined photo and video sharing websites, as are professional and business network websites (57\%), personal websites (48\%), blogs (46\%), online forums and communities $(34 \%)$ and even online gaming websites (27\%) (CROSS TAB January 2010).

Society for Human Resource Management (2013) research findings indicated that, LinkedIn remains the most commonly used social network websites by employers for screening and selecting job applicants (92\%), professional and association's social network websites (14\%), Facebook (58\%) and MySpace (4\%), Twitter (31\%). A recent survey conducted by Society for Human Resource Management (2014) also revealed that 77\% of recruiting professionals screened and selected job applicants by evaluating their profiles on social network websites

Also, Stoughton,Thompson, and Meade (2015) affirmed that social network websites and as earch engine such as Google are used by $27 \%-65 \%$ organizations to screen job applicants. Society for Human Resource Management (2013) research findings indicated that, LinkedIn remains the most commonly used social network websites by employers for screening and selecting job applicants (92\%), professional and association's social network websites (14\%), Facebook (58\%) and MySpace (4\%), Twitter (31\%). A recent survey conducted by Society for Human Resource Management (2014) also revealed that $77 \%$ of recruiting professionals screened and selected job applicants by evaluating their profiles on social network websites.

Why are employers interested in the profile information of job applicants? Human resource managers and recruiting professionals can form their opinion about a job applicant's personal qualities, professional skills,and even their moral values. The major areas of concern among employers on the information posted on social network profiles of job applicants includes: drinking or drug abuse, provocative or inappropriate information, poor communication skills, lying about qualification, discriminatory views, unprofessional names, linked to criminal behavior, disclosed of confidential information about former employer and insulting former employer (Causer, 2009).

Society for Human Resource Management (2013 cited in Segal, 2014) affirmed that, 74\% of surveyed employers were interested in the legal risk and protected characteristics, and $61 \%$ were concerned about whether job applicant is fit for the organization though 63\% are concern about the relevance of information obtained from social network websites. Meinert (2015) added that employers search social network websites for situational judgment test use, personality testing and behavioral rating scales. A survey revealed that the use of bad language posted on social network profile would negatively affect the hiring decision of $86 \%$ of employers (Fry, 2013). The same survey indicated that $82 \%$ and $81 \%$ of employers' hiring decision would be negatively affected by discriminatory views and inappropriate picture/ video respectively.

Further, a survey of recruiting professionals done by CROSS TAB (January 2010) indicated that 70\% of the survey recruiting professionals rejected job applicants based on the online their behavior or activities. Also, 58\% of surveyed recruiting professional revealed that job applicants were rejected based on their online lifestyle; inappropriate comments and text of job seekers also influence the rejection of $56 \%$ job applicants, and $55 \%$ were rejected due to unsuitable photos, videos, and information. Career Builder (2014) further affirmed that employers rejected job applicants resulting from information on inappropriate photographs, drug, and alcohol-related information, bad-mouthed previous employers/friends/colleagues or relatives, discriminatory comments on religion/gender/race, incorrect qualification, unprofessional screen name and linkages to criminal behavior posted on profiles of social networks and search engines.

Notwithstanding these negative effects of the use of social network profile for screening and selection by employers, job applicants can also benefit. That is when the findings of searching the social network profile happen to be favorable. When job applicants' historical digitalfootprints are favorable in terms of meeting the required skills, job related interest, competencies, professional experience, communication skills and even personal traits of a particular job or position in a consistent manner, employers will be encouraged to hire these job applicants (Betances, Solarczyk \& Belloows, 2012). Privacy settings may be activated but cannot provide enough protection of students' social network digital footprint from employers 
since many friends and networks may access, copy, paste or forward online profile information (Empower your students and yourself as digital citizens, 2012).

\subsection{Social Network Usage by Students and Awareness of It in Screening and Selection}

The means of communication between and among families, friends, workers, students, and lecturers are greatly influenced by the changing trends in technology especially online social networks. Social network websites were established to provide an avenue for the user to interact online through personal expression on the website profiles and even search engines' accounts.The use of social networks websites is growing per seconds. They have become the easiest, fastest and most convenient means of communication around the world. Social networks have reduced distance in communication and have enhanced quick interaction. They have also created bigger platforms for meeting and connecting with people from all corners of the world. Even businesses have taken advantage of these bigger platforms to market their goods and services.

Online social networks are fast changing the public discourse on the environment, politics, technology and entertainment due to the ease of use, speed and reach (Owusu-Acheaw \& Larson, 2015; Asur and Huberman, 2010). Minocha (2009) added that the use of social network enhances the sense of community of students.Nonetheless, students should also be concerned about their privacy and employment prospects at school. Peluchette and Karl (2008) commented that $50 \%$ of students have aprofile that indicates party lifestyle and includes pictures of profanity as well as alcohol. Perhaps students post these pictures and comments on their profile thinking that no one will see their post except those in his or her group. Shafie, Mansor, Osman, Nayan and Maesin (2011)explained that students were concerned about their privacy on the social networks but were less concerned about the content that impacts the career or profession. However, it was found that $80 \%$ of students surveyed were concerned about their current postings on social network profiles (Peluchette \& Karl, 2008).Additionally, Simply Hired (2012) revealed that $90 \%$ of job applicants believe their social network profiles are examined before they are called for interview.

\subsection{Theoretical Framework for the Use of Social Network Profile Information}

Theories are used to explain observable realities and facts that provide the basic constructs. Several theories explain the use of social networks construct. This research adopted the theories of reasoned action and planned behavior to explain the growing use of social networks by students and also the used of social network profiles by employers in screening and selection of job applicants.

The theory of reasoned action was developed to understand the relationships among attitudes, intentions, and behavior (Fishein, 1967). This theory postulates that behavioral intention is the most important determinant of behavior and individual's behavior intention constitute the attitude towards performing that behavior but this is subjective to the associated norm of the behavior.

Planned behavior theory also posits that the behavioral intention and attitude towards subjective norms are independent determinants of perceived control (Montano \& Kasprzyk, 2014). Therefore, the theories of reasoned action and planned behavior operate on causal relationships among behavioral beliefs, normative beliefs and control beliefs (Ajzen, 2006).

Many researchers have used the theory of planned behavior to predict several behaviors (Baker \& White, 2010;Stone, Jawahar \& Kisamore, 2010; Robinson \& Doverspike, 2006).Relating the theories of reasoned action and planned behavior to this research, it can be explained that, many University students are using social network websites due to the ease, convenience, popularity and acceptability by peers. Also, many employers are using social network websites profile information of job applicants due to a great deal of personal information posted on these profiles which can be accessed and assessed at minimal or no cost to validate or predict the behavior of job applicants. This is because job applicants' behavior on these social networks websites can give an incline of who they are or will be on the job.

\section{Methodology}

A survey research design was adopted for this research. The population of the study is Valley View University students,but the target population was the final year students. Final year students were selected due to their potential of becoming job applicants immediately after school. A sample of 207 final year students from regular, sandwich and distance educationwere surveyed from the business classes

Primary data was collected through a questionnaire. The questionnaire items were designed based on the research questions. Hence the questionnaire was divided into four sections. Section A for demographic data, section B for students awareness of employers usage of social network website profile in the screening and selection of job applicants, section C covers students behavior on social network websites and section D deals with the approval of employers usage of social network website profiles in the screening and selection of job applicants. To ensure validity and reliability of research instrument, validated questionnaire items that reliably measured the research variables were used. The copies of the questionnaire were administered to all modes of final year classes of students in the School of Business. Students were allowed some time to fill the copies of the questionnaire after which they were collected. All copies were fully completed and collected representing hundred percent response rate.

The data collected was analyzed by using descriptive statistics (frequency distribution tables), linear and log it regression models. 
- Modeling the influence of Students' Awareness of Social Network Profile Evaluation (SASNPE) by employers on Students Social Network Behavior (SSNB)

Since age, network, security and most interacted person are in different categories, we created dummies for each category and estimated the regression model as follows:

$$
b e \square \text { ave }_{i}=\alpha_{0}+\alpha_{1} \text { Aware }_{I}+\beta_{i} \sum_{i=2}^{4} D_{1 i}+\alpha_{2} \text { Gender }_{i}+\gamma_{i} \sum_{i=2}^{4} D_{2 i}+\delta_{i} \sum_{i=2}^{5} D_{3 i}+\varepsilon_{i} \sum_{i=2}^{4} D_{2 i}+\alpha_{3} G P A_{i}+u_{i}
$$

Where

$$
D_{1 i}, D_{2 i}, D_{3 i}, D_{4 i} \text { are dummies for Age, Network, Security and Most interacted person online }
$$

- Modeling the influence of Students' Social Network Behavior (SSNB) on Students' Approval of Employer Usage of Social Network Profile (AEUSNP) in screening and selection

Following Long and Freese (2001), assuming a latent variable $y^{*}$ ranging from $-\infty$ to $\infty$, related to $y$ as $y^{*}=x^{\prime} \beta+\varepsilon$

The relationship between the latent variable and the observed value is $y= \begin{cases}1 \text { if } y^{*}>0 \\ 0 \text { if } y^{*} \leq 0\end{cases}$

For a given set of explanatory variables, we would see that $\operatorname{Pr}(y=1 \mid x)=\operatorname{Pr}\left(y^{*}>0 \mid x\right)$

Substituting $y^{*}=x^{\prime} \beta+\varepsilon$, we will obtain $\operatorname{Pr}(y=1 \mid x)=\operatorname{Pr}\left(\varepsilon>-\left[x^{\prime} \beta\right] \mid x\right)$

If we assume that $\varepsilon$ is logistically distributed with $\operatorname{var}(\varepsilon)=\frac{\pi^{2}}{3}$, we would obtain the logit model $\operatorname{Pr}(y=1 \mid x)=\frac{\exp \left(x^{\prime} \beta\right)}{1+\exp \left(x^{\prime} \beta\right)}$

We can construct a model in which the predicted $\operatorname{Pr}(y=1 \mid x)$ would be within the ranges from 0 to 1.Using this idea, we transform the probabilities into odds (indicating how often an event happen relative to how often it does not happen); that is, how often an individual shows good social network behavior relative to how often the individual does not as

$$
\Omega(x)=\frac{\operatorname{Pr}((y=1 \mid x))}{\operatorname{Pr}(y=0 \mid x)}=\frac{\operatorname{Pr}((y=1 \mid x))}{1-\operatorname{Pr}(y=1 \mid x)}
$$

In econometric modeling of the influence of Students' Social Network Behavior (SSNB) on Students' Approval of Social Network Profile Evaluation(SASNPE) in screening and selection by employers, we estimate the probability that the students would exhibit SASNPE as $\operatorname{Pr}(y=1)=\Lambda\left(\beta_{0}+\beta_{1} S S N B_{i}+\beta_{2} G P A_{i}+\beta_{3}\right.$ Gender $_{i}+\beta_{4}$ Age $_{i}+\beta_{5} S N B_{i}+\beta_{6}$ Privacy $\left._{i}\right)$,

where $\Lambda$ is the logistic cdf for the logit model, $S S N B_{i}=$ students social network behavior measured as the sum of 8 different behavior ( all measured as $1=$ yes or $0=$ no); $G P A_{i}=$ Grade average point of students (measured as $1=1.5$ and below, $2=1.5$ 2.0, $3=2.1-2.5,4=2.6-3.0,5=3.1-3.5$, and $6=3.6-4.0$ ); Gender $_{i}=$ Gender of students; Age $_{i}=$ Age of students (measured as 1 for 20 years and below, 2 for 21-25 years, 3 for 26-30 years, 4 for 31-35 years, and 5 for 36 years and above); and Privacy $_{i}=$ student concerned about privacy.

$\operatorname{SASNPE}_{i}=$ Students' Approval of Social Network Profile Evaluation is the dependent variable measured as $1=$ yes, $0=$ no

\section{Presentation of Data and Discussion}

This section presents the demographic data of respondents and descriptive statistics with the help of frequency distributive tables to provide detail information about each relevant variable. More so,it presents the analyses, interpretation, and discussions of linear and log it regression results objective by objective.

\subsection{Data Presentation, Analysis, And Discussion}

\subsubsection{Demographic Data of Respondents}

\begin{tabular}{|c|c|c|c|}
\hline & Frequency & Percent Cumulative & Percent \\
\hline Male & 106 & 51.2 & 51.2 \\
\hline Female & 101 & 48.8 & 100.0 \\
\hline
\end{tabular}

Table 1: Gender of Respondents

Table 1 indicates a total of 120 respondents consisting of 106 and 101 males and females representing $51.2 \%$ and $48.8 \%$ respectively. 


\begin{tabular}{|c|c|c|c|}
\hline & Frequency & Percent Cumulative & Percent \\
\hline 20 Years And Bellow & 10 & 4.82 & 4.8 \\
\hline 21-25 Years & 111 & 53.6 & 88.4 \\
\hline 26-30 Years & 60 & 29.0 & 82.4 \\
\hline 31-35 Years & 15 & 7.3 & 100.0 \\
\hline 36 Years And Above & 11 & 5.3 & \\
\hline
\end{tabular}

Table 2: Age Range of Respondents

Table 2 shows the age distribution of respondents. Majority of the respondents falls within the age range of 21-25 years representing $53.6 \%$.

\begin{tabular}{|c|c|c|c|}
\hline & Frequency & PercentCumulative & Percent \\
\hline WhatsApp & 180 & 87.0 & 87.0 \\
\hline Facebook & 19 & 9.2 & 96.2 \\
\hline Twitter & 3 & 1.4 & 97.6 \\
\hline YouTube & 2 & 1.0 & 100.6 \\
\hline Others & 3 & 1.4 & 1.4 \\
\hline
\end{tabular}

Table 3: Mostly Used Social Network

Table 3 also reveals that the mostly used social network by respondents is WhatsApp with $87.0 \%$. Though the respondents make use of Facebook, Twitter, YouTube, LinkedIn and other social networks, WhatsApp is the mostly used social network.

\begin{tabular}{|c|c|c|c|}
\hline & Frequency & PercentCumulative & Percent \\
\hline Friends & 174 & 84.1 & 84.1 \\
\hline Family & 29 & 14.0 & 98.1 \\
\hline Lecturers & 3 & 1.4 & 99.5 \\
\hline Others & 1 & .5 & 100.0 \\
\hline
\end{tabular}

Table 4: People Mostly Interacted with on Social Network

Respondents interact with friends, families, lecturers, and others on the social network but mostly with friends as indicated in table 4 . Hence, $84.1 \%$ of the respondents interact mostly with their friends on their most used social network.

\begin{tabular}{|c|c|c|c|}
\hline & Frequency & Percent Cumulative & Percent \\
\hline Very secured & 45 & 21.7 & 21.7 \\
\hline Secured & 92 & 44.4 & 66.1 \\
\hline Somehow secured & 57 & 27.5 & 93.6 \\
\hline Not secured at all & 13 & 6.3 & 100.0 \\
\hline
\end{tabular}

Table 5: Security of Social Network Profile

Concerning the security of the social network profile information of respondents, a cumulative percent of 66.1 them believes that their information posted is secured and $27.5 \%$ indicates that their profile information is somehow secured

\begin{tabular}{|c|c|c|c|}
\hline & Frequency & PercentCumulative & Percent \\
\hline 1.5 and bellow & 4 & 1.9 & 1.9 \\
\hline $1.6-2.0$ & 6 & 2.9 & 4.8 \\
\hline $2.1-2.5$ & 26 & 12.6 & 17.4 \\
\hline $2.6-3.0$ & 77 & 37.2 & 54.6 \\
\hline $3.1-3.5$ & 72 & 34.8 & 89.4 \\
\hline $3.6-4.0$ & 22 & 10.6 & 100.0 \\
\hline
\end{tabular}

Table 6: GPA Range of Respondents

Table 6 reveals that the majority of the respondents' GPA falls within 2.6-4.0 and 149 of the respondents representing $72.0 \%$ have GPA within the GPA range of 2.6-3.5. The GPA range is based on 4-grade point. Therefore the majority of the respondents are between second class lower and second class upper. 


\begin{tabular}{|c|c|c|c|c|c|}
\hline & \multicolumn{2}{|c|}{ Frequency } & \multicolumn{2}{c|}{ Percent } & $\begin{array}{c}\text { Cumulative } \\
\text { Percent }\end{array}$ \\
\hline & No & Yes & No & Yes & \\
\hline Awareness & 22 & 185 & 10.6 & 89.4 & 100 \\
\hline Concerned about privacy & 24 & 183 & 11.6 & 88.4 & 100 \\
\hline Approval & 98 & 109 & 47.3 & 52.7 & 100 \\
\hline
\end{tabular}

Table 7: Respondents' Awareness, Concerned about Privacy and Approval of the

Use of Social Network Profile in Screening and Selection by Employers

Table 7 shows the respondents awareness of employers using social network profiles of job applicants in screening and selection. It also shows respondents' concerned about the privacy of their social network profiles and their approval of employers' usage of social network profiles in the screening and selection of job applicants for employment. Majority of the respondents with $89.4 \%$ are aware of the use of social network profiles in the screening and selection of job applicants. Moreover, $88.4 \%$ of respondents are concerned about the privacy of their social network profile. However, $47.3 \%$ of respondents approved the use of social network profiles in screening and selecting job applicants and $52.7 \%$ disapproved the use of social network profiles of job applicants in screening and selection by employers.

\begin{tabular}{|c|c|c|c|c|c|}
\hline & \multicolumn{3}{|c|}{ Frequency } & Percent & Cumulative \\
\hline & No & Yes & No & \multicolumn{2}{|c|}{ Yes Percent } \\
\hline $\begin{array}{c}\text { Posted provocative/inappropriate } \\
\text { picture/video }\end{array}$ & 18423 & 88.9 & 11.1 & & 100 \\
\hline Posted information about drinking & 17928 & 86.5 & 13.5 & & 100 \\
\hline $\begin{array}{l}\text { Posted information about substance } \\
\text { abuse }\end{array}$ & 15453 & 74.4 & 25.6 & & 100 \\
\hline $\begin{array}{c}\text { Have bad mouthed } \\
\text { friends/colleagues/relatives }\end{array}$ & 16938 & 81.6 & 18.4 & & 100 \\
\hline $\begin{array}{c}\text { Posted discriminating } \\
\text { comment(race, gender, religion) }\end{array}$ & 14463 & 69.6 & 30.4 & & 100 \\
\hline Posted unprofessional name & 14364 & 69.1 & 30.9 & & 100 \\
\hline $\begin{array}{c}\text { Have been tagged inappropriate } \\
\text { picture/ video }\end{array}$ & 12978 & 62.3 & 37.7 & & 100 \\
\hline $\begin{array}{l}\text { Have tagged someone with } \\
\text { inappropriate picture/ video }\end{array}$ & 17136 & 82.6 & 17.4 & & 100 \\
\hline
\end{tabular}

Table 8: Respondents' Social Network Behavior (SSNB)

The main areas of concerned to employers in reviewing the profiles of job applicants comprise the statements in Table8. Table 8, therefore, shows that $88.9 \%, 86.5 \%$ and $74.4 \%$ of respondents did not post provocative/inappropriate pictures/video, information about drinking and substance abuse respectively. More so, $81.6 \%, 69.6 \%$ and $69.1 \%$ of respondents respectively have not bad-mouthed friends/colleagues or relatives and did not post discriminatory comments and did not post the unprofessional name on the social networks. Moreover, $62.3 \%$ and $82.6 \%$ of respondents have not been tagged and have not tagged people with inappropriate picture/video on social network profile.

\subsection{Inferential Statistics}

\begin{tabular}{|c|c|c|c|}
\hline Variable & Coeff & $\mathbf{S E}$ & P Values \\
\hline SASNPE & -.417 & .418 & .321 \\
\hline \multicolumn{4}{|l|}{ Age (Omitted category, 20years and below) } \\
\hline $21-25$ years & .538 & .614 & .382 \\
\hline $26-30$ years & .824 & .656 & .211 \\
\hline 31-35 years & -.556 & .763 & .467 \\
\hline 36 years and above & .155 & .866 & .858 \\
\hline Gender & -.368 & .262 & .162 \\
\hline Network (Omitted category, Whatsapp) & & & .467 \\
\hline
\end{tabular}




\begin{tabular}{|c|c|c|c|}
\hline Variable & Coeff & S E & P Values \\
\hline Facebook & .033 & .443 & .940 \\
\hline Twitter & -1.176 & 1.050 & .979 \\
\hline YouTube & .035 & 1.345 & .550 \\
\hline Others & .739 & 1.234 & $.009^{*}$ \\
\hline GPA & .341 & .130 & \\
\hline Security of Social Network & & & .894 \\
\hline Somehow secured & & .572 \\
\hline Secured & .045 & .339 & .877 \\
\hline Very secured & -.206 & .365 & .608 \\
\hline Most interacted person: & -.093 & & .283 \\
\hline Family & & & .596 \\
\hline Lecturer & & .363 & .001 \\
\hline Others &. .590 & 1.119 & \\
\hline Constant & -1.076 & 1.988 & \\
\hline
\end{tabular}

Table 9: Influence of Students' Awareness of Social Network Profile

Evaluation (SASNPE) OfJob Applicants on Student Social Network Behavior (SSNB) N = 207

$$
F(17,189)=1.54 \text { Prob. }>F=.0846 R 2=.122
$$

Root MSE $=1.7729^{*}$ Variable Has Significant Influence Student Social Network Behavior SASNPE = Students' Awareness of Social Network Profile Evaluation

Table 9 indicates the influence of SASNPE of job applicants by employers on SSNB. The table shows that, SASNPE of job applicants negatively correlate with SSNB at -.417 but not significant since the p-value is greater than $5 \%$. Also, Age, Gender, Network, GPA, Security and the most interacted personcan influence SSNB at $P$ values as indicated in table 9respectively but are all insignificant except GPA. That means high GPA significantly influences student's behaviour on thesocial networks. This is revealed by the p-value of .009. All other factors have higher $P$ values and have no significant influence on students' social network behavior. Some of the factors have negative correlation but at aninsignificant level.

Regarding the hypothesis one, we accept that students' awareness of social network profile evaluation of job applicants in screening and selection by employers has no significant influence on students' social network behavior. Nonetheless, students' awareness, the type of network mostly used, how secured the network is,gender and GPA can influence students' social network behaviorbut not significantly except GPA.

\begin{tabular}{|c|c|c|c|}
\hline Variables & Odds Ratio & S. E & P Values \\
\hline $\begin{array}{c}\text { Social Network Behavior } \\
\text { (SNB) }\end{array}$ & .952 & .081 & .565 \\
\hline $\begin{array}{c}\text { Age (Omitted category, } \\
\text { 20years and below) }\end{array}$ & & & .208 \\
\hline $21-25$ years & .383 & .291 & .760 \\
\hline $26-30$ years & .784 & .624 & .286 \\
\hline $31-35$ years & -.379 & .344 & .324 \\
\hline 36 years and above & .380 & .370 & .708 \\
\hline Gender & .938 & .278 & .379 \\
\hline Privacy & .845 & .379 & .479 \\
\hline Security of Social Network & & & .785 \\
\hline Somehow secured & 1.346 & .508 & .852 \\
\hline Secured & 1.330 & .540 & .370 \\
\hline Very secured & 1.194 & .779 & .139 \\
\hline GPA & .973 & 2.92 & \\
\hline Constant & 2.669 & & \\
\hline
\end{tabular}

Table 10: Influence of Students' Social Network Behavior on Approval of

Employer Usage of Social Network Profile Evaluation No of Observations $=207$

Wald Chi2 (11) $=0.668$, Probability $>$ Chi2 $=.8240$, Pseudo $R 2=.0251$ 
The influence of students' social network behavior on students' approval of social network profile evaluation by employersis indicated in table 10. All the variables have less odds ratio of influence and high $\mathrm{p}$ values. Low odds ratios with high p values mean that social network behavior, age, gender, privacy,and GPA have insignificant influence on the approval of the use of social network profile evaluation by employers in screening potential employees.However, the security level of social network profile has high odds ratios meaning that students perception of how secured the profiles are on social network influence their social network behavior.

Given the presentation in table 10, hypothesis two is accepted that students' social network behavior has no significant influence on students' approval of employers' use of social network profile evaluation in screening and selection job applicants). However, given the odds ratios of social network behavior, gender, privacy, security and GPA, students approval of employers' use of social network profile in screening and selection of job applicants can be influenced but not at significant levels.

\section{Discussion of Findings}

The first purpose of this study is to provide ananswer to the level of students' awareness of employers using the social network profiles information of job applicants before hiring job applicants. It was foundthat $89.4 \%$ of respondents are aware and $10.6 \%$ are not aware of employers using social network profile information of job applicants in screening and selection for employment. Also, 88.4\% are concerned about the privacy of their social network profile as depicted in table 7 .

Secondly, the study seeks to answer the extent to which students' awareness of social network profile evaluation in screening and selection of job applicants by employers influences their social network behavior. The regression results revealed in tables 9 and 10 that, students' awareness of employers using social network profile information of job applicants influence their social network behavior but insignificantly. The control factors (students' approval of the use of social network profile information in screening and selection, most used social network and GPA of students, and gender) that influence students' social network behavior were all at insignificant level except GPA. It can, therefore,be inferredthat students with higher GPA exhibit good social network behavior. Moreover, female students exhibit better social network behavior than male students as indicated in table 9.

Thirdly, the research seeks to assess the influence of students' social network behavior on students' approval of the use of social network profiles in the screening and selection of job applicants by employers. It was revealed that, given the social network behavior of students' at odds ratio of .952, 52.7\% of students will approve employers use of social network profile information of job applicants in the screening and selection and $47.3 \%$ will disapproved though $88.4 \%$ are concerned about the privacy of their social network profile as shown in table 7.This may be motivated by the difficulty in getting ajob after school. That is students' awareness of employers using social network profile information of job applicants in screening and selection influences students' social network behavior but at an insignificant level as revealed table 10.

Among the factors that can influence students' social network behavior on the approval of employers' use of social network profile, social network behavior, gender, type of network, concerned for privacy and GPA all insignificantly influence students' approval regarding employer usage of social network profile in screening and selection.

Aligning the research these findings to other studies, Simply Hired (2012) revealed that $90 \%$ of job applicants believe their social network profiles are examined before they are called for interview. Shafie, Mansor, Osman, Nayan and Maesin (2011) explained that students were concerned about their privacy on thesocial networks but were less concerned about the content that impacts the career or profession.

Moreover, this research results confirmed the study of Peluchette and Karl (2008) which found that $80 \%$ of students surveyed were concerned about their current postings on social network profiles. That is, privacy settings may be activated but cannot provide enough protection of students' social network digital footprint from employers since many friends and networks may access, copy, paste or forward online profile information (Empower your students and yourself as digital citizens, 2012).

\section{Conclusion and Recommendations}

This study investigated students' awareness of the use of social network profile information of job applicants by employers on students' social network behavior and the influence of students' social network behavior on their approval of employers using job applicants' social network profile in screening and selection. It is concludedthat students' awareness of the use of social network profile information of job applicants by employers, influences students' social network behavior but at aninsignificant level. Also, students' social network behavior insignificantly influences their approval of employers using job applicants' social network profile in screening and selection. Further, High GPA and female students exhibit good behavior social network.

Students awareness of the SNPE influence their behavior especial those with higher GPA,but their SNB does not significantly influence their approval of SNPE by employees in screening and selecting potential employees.

Based on the findings of the study, it is recommended that students should be mindful of their behavior on thesocial networks since bad social network behavior can deny them their job.

Academic administrators can take a clue from this research for policies concerning the use of social network websites in Universities. That is, there is a correlation between poor performance and bad social network behavior of students. 
Academic advisors and counselors should also use findings of this research for helping students achieve their career goals. Employers should be circumspect about the use of social network profile information in screening and selection since informationobtainable may infringe upon the privacy of social network users.

\section{References}

i. Ajzen, I. (2006). Constructing a TPB questionnaire: Conceptual and methodological considerations. Retrieved from www.people.umass.edu/aizen/pdf/tpb.measurement.pdf.

ii. Asur, S., \& Huberman, B. A. (2010). Predicting the future with social media. Social Computing Lab: HP Labs, Palo Alto, California. Pp 1- 8.

iii. Baker, R., \& White, K. (2010). Predicting adolescents' use of social networking sites from an extended theory of planned behavior perspective. Computers in Human Behavior, 26, 1591-1597. doi: 10.1016/j.chb.2010.06.006

iv. Belluck, P. (June 22, 2006). Young People's Web Postings Worry Summer Camp Directors, N.Y. TIMES.

v. Betances, D., Solarczyk, R., \& Bellows, C. (2012). Personal social networking: Affects on companies hiring decisions. MBA Student Scholarship. Retrieved on 16 January 2017 from http://scholarsarchive.jwu.edu/mba_student/9

vi. Broughton, A., Foley, B., Lendermaier, S., \& Cox, A. (2013).The use of social media in the recruitment process. Acas Research Publications. UK:Brighton. Retrieved from www.acas.or.uk/researchpapers

vii. Brown, V., \& Vaughn, D. (2011). The writing on the (Facebook) wall: The use of social networking sites in hiring decisions. Journal of Business Psychology, 26(2) 219-225.

viii. Career Builder. (2014). Number of employers passing on applicants due to social media posts continues to rise. New CareerBuilder Survey, 1.

ix. Causer, C. (2009). Social networking profiles: Are you showing your best side? IEEE Potentials, May/June 2009, 10-12

x. CROSS-TAB (Jan. 2010). Online Reputation in a Connected World. Retrieved from http://go.microsoft.com/ ?linkid=9709510.

xi. Empower your students and yourself as digital citizens. (2012). American Teacher, 96(5), 4.

xii. Fishbein, M. ( 1967) (ed.). Readings in attitude theory and measurement. New York: Wiley.

xiii. Golbeck, J., Robles, C., \& Turner, K. (2011). Predicting personality with social media.Proceedings of the 2011 annual conference extended abstracts on Human factors in computing systems (pp. 253-262). Vancouver: ACM.

xiv. Kaplan, A. \& Haenlein, M. (2010). Users of the world unite! The challenges and opportunities of social media. Business Horizons, 53(1), 59-68.

xv. Kluemper, D. H., \& Rosen, P. A. (2009). Future employment selection methods: evaluating social networking web sites. Journal of Managerial Psychology, 24(6), 567-580. DOI 10.1108/02683940910974134

xvi. Laudon, C. \& Traver, C. G. (2014). E-commerce: Business, technology and society (10 ${ }^{\text {th }}$ ed.). Pearson Education, Inc., One Lake Street, Upper Saddle River, New Jersey 07458.

xvii. Long, J.S. and Freese, J. (2001): Regression Models for Categorical Dependent Variables Using Stata. College Station [Texas], Stata Corporation.

xviii. McFarland, L. A., \& Plohart, R. E. (2015). Social media: A contextual framework to guide research and practice. Journal of Applied Psychology, 11(6), 1653-1677.

xix. Meinert, D. (2015). Heads up. HR Magazine, 6, 88-98.

xx. Montano, D., \& Kasprzyk, D. (2014). Theory of reasoned action, theory of planned behavior and integrated behavior model.

xxi. Nye, C. D., Do, B., Drasgow, F., \& Fine, S. (2008). Two-step testing in employee selection: Is score inflation a problem? International Journal of Selection and Assessment, 6(2), 112-120.

xxii. Owusu-Acheaw, M., \& Larson, A. G. (2015). The use of social media and its impact on academic performance of tertiary institution students: A case students of students from Koforidua Polytechnic, Ghana. Journal of Education and Practice, 6(6), 96-102.

xxiii. Peluchette, J. \& Katherine, K. (2008). Social Networking Profiles: An examination of student attitudes regarding use and appropriateness of content. Cyber psychology\& behavior. Business Source Complete, 11(1), 95-97.

xxiv. Peters, K., Chen, Y., Kaplan, A. M., Ognibeni, B., \& Pauwels, K. (2013). Social media metrics-A framework and guidelines for managing social media. Journal of Interactive Marketing, 27(2013), 281-298. Retrieved from www.sciencedirect.com

xxv. Pew Research Center (February 2016). Smartphone ownership and internet usage continue to climb in emerging economies. Retrieved from www.pewresearch.org

xxvi. Robinson, R., \& Doverspike, D. (2006). Factors predicting the choice of an online versus a traditional course. Computers in Teaching, 33(1), 64-68. doi:10.1207/s15328023top3301_10

xxvii. Segal, J. A. (2014). Social Media Use in Hiring: Assessing the Risks,. In HR Magazine. The Societyof Human Resource Management.

xxviii. Simply Hired (2012). Today's Job Seeker Report. A survey of job seeker behaviors and motivations, 2012 Edition. Retrieved from http://success.simplyhired.com/rs/simplyhired/images/TodaysJobSeekerReport_2 012_US.pdf 
xxix. Shafie, L. A., Mansor, M., Osman, N., Nayan, S. \& Maesin, A. (2011). Privacy, trust and social network sites of university students in Malaysia. Research Journal of International Studies, 20, 11-20

xxx. Stone, T., Jawahar, I., \& Kisamore, J. (2010). Predicting academic misconduct intentions and behavior using the theory of planned behavior and personality.Basic and Applied Social Psychology, 32(1), 35-45. doi: 10.1080./01973530903539895

xxxi. Stoughton, J. W., Thompson, L. F., \& Meade, A. W. (2015). Examining applicant reactions to the use of social networking websites in pre-employment screening. Journal of Business and Psychology, 30, 73-88.

xxxii. Sumner, C., Byers, A., \& Shearing, M. (2011). Determining personality traits and privacy concerns from Facebook activity. Online Privacy Foundation, United Arab Emirates: Abu Dhabi

xxxiii. Viswesvaran, C. (2003). Introduction to special issue: Role of technology in shaping the future of staffing and assessment. International Journal of Selection and Assessment, 11, 107-112. 